\title{
LA INTERVENCIÓN DEL TERCERO EN EL PROCESO CIVIL PERUANO
}

Enrique Palacios Pareja

\section{Conceptos básicos para el desarrollo del tema}

\subsection{La intervención}

En principio, el proceso produce normalmente sus efectos solamente entre aquellos que han sido parte de él, de suerte que si no ha sido instaurado por parte de un determinado sujeto o en su contra, no hay necesidad jurídica de que el proceso se amplíe respecto de él. Sin embargo, como señala Michelli ${ }^{1}, \ll \ldots$ la conexión entre relaciones y situaciones jurídicas de un lado y razones de economía procesal, de otro, han aconsejado al legislador a admitir la posibilidad de que el tercero pueda entrar en el proceso, si quiere, o que una de las partes haga el llamamiento, o que el juez convoque al tercero".

De este modo, se quiebra el viejo aforismo romano «res inter alios iudicata tertiis non nocet», en virtud del cual los efectos del proceso sólo alcanzan a quienes, como demandante o demandado, participaron en el proceso.

En efecto, con la intervención se busca que una persona distinta del actor y del demandado pueda participar en el proceso en trámite en el que estos son partes originarias, ya sea interviniendo voluntariamente para ayudar a alguna de las partes originarias en resguardo de un interés propio que

1 Michell, Gian Antonio, Curso de Derecho procesal civil, Ediciones Jurídicas Europa-América, Buenos Aires, 1970, tomo I, pág. 226. 
puede verse afectado de manera indirecta con la decisión judicial, o para defender derechos propios que se discuten en el proceso y que concuerdan en todo o en parte con los afirmados por uno de los sujetos del proceso, o para introducir una nueva pretensión oponible a la de las partes originarias. Asimismo, puede producirse la intervención ya no por voluntad del tercero, sino forzadamente, en cuyo caso el tercero participará en el proceso como consecuencia de un llamado del juez, ya sea a pedido de parte o de oficio.

Es justamente de acuerdo a de quién proviene la solicitud de ingreso al proceso, que la intervención se clasifica en voluntaria o espontánea, cuando es el propio tercero interviniente quien solicita su incorporación al proceso; o necesaria o provocada, cuando es el juez, por propia iniciativa o por pedido de alguna de las partes originarias, quien llama al tercero para que ingrese al proceso.

De otro lado, el grado de interés del tercero respecto de la relación sustantiva subyacente en el proceso (conocido en doctrina como interés jurídico relevante), determina la clasificación doctrinaria de la intervención de terceros en principal y accesoria, subdividiéndose la primera en intervención de tercerista o ad excludendum y en intervención litisconsorcial.

Antiguamente se distinguía entre intervención principal e intervención adhesiva. La intervención adhesiva era dividida a su vez en adhesión autónoma, cuando el tercero se apoyaba en las razones de una de las partes alegando un derecho propio discutido en el proceso, y en adhesión dependiente, cuando el tercero no invocaba un derecho propio, limitándose a ayudar a una de las partes. Esta clasificación ha sido sustituida por la de intervención principal e intervención accesoria. En la primera se encuentran comprendidos tanto el tercero que interviene en el proceso aduciendo un derecho propio opuesto al de las partes, o al de alguna de ellas ${ }^{2}$, llamado interviniente principal ad excludendum, como el tercero que interviene apoyándose en las razones de una de las partes alegando un derecho propio coincidente con el de ésta ${ }^{3}$, llamado interviniente litisconsorcial. La inter-

${ }^{2}$ Intervención excluyente principal e intervención excluyente de derecho preferente, previstas en los artículos 99 y 100 del Código Procesal Civil peruano, respectivamente.

${ }^{3}$ Intervención litisconsorcial prevista en el artículo 98 del Código Procesal Civil peruano. 
vención accesoria comprende al tercero que interviene sin alegar derecho propio, ayudando a la parte con el fin de evitar efectos secundarios o reflejos de la sentencia, que afecten su relación sustancial con la parte a la que ayuda $^{4}$; a este tercero se le conoce como interviniente adhesivo o coadyuvante.

Como puede apreciarse, la diferencia entre la antigua clasificación y la que la sustituyó, es que en la primera se incluía dentro de la intervención adhesiva al interviniente litisconsorcial, el que si bien es adhesivo en cuanto une su suerte a la de una de las partes, es sustancialmente un interviniente principal, pues pretende un derecho que, aunque coincidente con el de su litisconsorte, es propio y reclama que sea reconocido en la misma sentencia. En consecuencia, debe considerarse el interviniente litisconsorcial como principal.

La palabra intervención, etimológicamente expresa la sobrevinencia de otras partes en una relación ya iniciada sin ellas (inter $=$ durante). Es necesario pues, para que se dé la intervención, que el proceso en que se interviene esté iniciado, para que durante su vigencia suceda el ingreso de aquella persona que no era parte en dicho proceso. No podría hablarse de intervención de tercero antes de la iniciación del proceso, pues si el ingreso de la persona se da en ese momento o al iniciarse el mismo, entonces ya no hay intervención, pues siempre se habrá tenido la calidad de parte. Obviamente, carece también de sentido la intervención de tercero en un proceso que ha terminado. Esta condición de preexistencia del proceso pendiente entre otras partes constituye uno de los supuestos fundamentales de la intervención.

Otro supuesto imprescindible es que el interviniente sea un tercero, condición que desaparecerá al ser aceptąa su intervención ${ }^{5}$.

4 Intervención coadyuvante prevista en el artículo 97 del Código Procesal Civil peruano.

5 En este sentido discrepamos del destacado jurista nacional Juan Monroy, quien al tratar sobre la intervención adhesiva y la intervención litisconsorcial sostiene que el interviniente no es parte, condición que sí le reconoce al interviniente excluyente. (Ver lus et Veritas, año IV, n. ${ }^{\circ}$, pág. 52). 
Por último, el tercero debe acreditar un interés propio y actual en el proceso, y dependiendo del grado de dicho interés podrá participar en el proceso, ya sea adhesiva, litisconsorcial o excluyentemente.

Sin que implique desconocer las obvias ventajas que ocasionará la regulación legislativa de la intervención de terceros, coincidimos con Véscovi ${ }^{6}$ en el sentido de que esta institución procesal supone una complicación del procedimiento, que incluso puede utilizarse para prolongar éste, hasta en colusión con alguna de las partes. Por ello, el mismo Véscovi ${ }^{7}$ aconseja un criterio restrictivo por parte de la judicatura para la admisión de la participación del tercero en el proceso, la cual deberá ser decidida por el juez en resolución debidamente motivada, la que se sustentará, fundamentalmente, en el grado de interés que tiene el tercero en el proceso.

\subsection{Las partes}

Resulta de particular importancia analizar el concepto de parte, como contrapartida del concepto tercero, pues en cada momento del proceso son terceros aquellos quienes no tienen la calidad de parte.

En principio el proceso tiene dos sujetos o partes: actor y demandado, los mismos que adquieren tal condición al momento de constituirse la relación jurídica procesal mediante el auto admisorio de la instancia y su notificación a quienes en él sean llamados al juicio como demandante o demandados. Obviamente, para considerar quiénes son parte en el juicio debe considerarse la situación jurídica y no la concurrencia personal al proceso, pues por ejemplo el representado, a pesar de que no interviene personalmente en el juicio, es parte en él.

Las partes pueden clasificarse de la siguiente manera:

a) En relación al momento mismo en que intervienen en la relación procesal:

- VésCovi, Enrique, Teoría general del proceso, Editorial Themis Librería, Bogotá, 1984, pág. 203.

7 Loc. cit. 
- Partes originarias: aquellas que figuran en el proceso desde su iniciación.

- Partes intervinientes: aquellas que vienen a figurar en el proceso después de haberse trabado la relación procesal entre las partes originarias.

b) En relación a su permanencia en el proceso:

- Partes permanentes: las que figuran en el proceso desde su inicio hasta su finalización.

- Partes transitorias: las que intervienen en algunas etapas del proceso.

c) De acuerdo a la función que desarrollan o su trascendencia en el proceso:

- Partes principales: aquellas que en el proceso están controvirtiendo un derecho suyo, independiente y autónomo.

- Partes secundarias: las que no alegan un derecho suyo, pero a quienes la derrota del titular del derecho alegado puede ocasionarles perjuicios.

d) Según su vinculación en el proceso:

- Partes necesarias: se quedan ligadas indispensablemente a la relación jurídica procesal, cuando la ley les da el carácter de partes.

- Partes voluntarias: cuando concurren al proceso voluntariamente, y su ausencia no afecta la válida integración de la relación jurídica procesal.

De otro lado, un muy importante sector de la doctrina procesal, entre ellos Carnelutti ${ }^{8}$, distingue dos nociones de parte: la noción pasiva y la noción activa, o lo que se conoce también como parte material y parte proce-

8 Carnelutti, Francesco, Instituciones del proceso civil, Ediciones Jurídicas Europa-América, Buenos Aires, 1973, tomo I, pág. 174. 
sal, reguladas respectivamente en los artículos 57 y 58 del Código Procesal Civil peruano. Por la noción pasiva o parte material, se entiende a ésta como parte de la relación jurídica material objeto de la litis, es decir, aquellos sujetos de la litis o de la relación sustancial que están sujetos al proceso, pero no son necesariamente sujetos del proceso, en el sentido de que sufren sus efectos pero no participan activamente en él.

Ahora bien, como los efectos del resultado del proceso benefician o perjudican a la parte material, ésta es estimulada por aquél a realizar actos necesarios o en todo caso sumamente útiles al proceso, con lo cual pasa a tener una participación activa en él. Así, la parte sujeto de la litis o del negocio (noción pasiva) pasa a ser sujeto del proceso, en el sentido de que es una de las personas que le prestan su obra, que hacen el proceso. De este modo, junto a la noción pasiva se perfila la noción activa.

En consecuencia, la palabra parte tiene un doble significado, denominándose parte en sentido material al sujeto de la litis (o relación sustancial) y parte en sentido procesal al sujeto del proceso.

Sobre el particular, no resulta infrecuente que la parte en sentido material no se encuentre presente en un proceso en el que se discute acerca de la relación sustancial de la cual ella es sujeto, en cuyo caso estaremos ante una persona que es parte en sentido material pero no es parte en sentido procesal, pues no ha participado en el proceso. Este sujeto será entonces un tercero en sentido procesal, pero legitimado para intervenir en el proceso, ya que el resultado del mismo afectará sus intereses; y a partir de que intervenga dejará de ser un tercero en el proceso para convertirse en parte procesal. Por ello, pueden existir personas que siendo terceros en el proceso sean parte en sentido material, situación que se mantendrá mientras permanezcan ausentes del proceso. Una vez aceptada su intervención, asumirán la condición de parte procesal.

Con respecto a la noción de parte en sentido procesal, Redenti ${ }^{9}$ nos enseña: «Parte en sentido procesal viene a ser aquel que promueve en nombre propio o en cuyo nombre se promueva, por su representante o apodera-

9 REDENTI, Enrico, Derecho procesal civil, Ediciones Europa-América, Buenos Aires, 1957, tomo I, pág. 181. 
do, y aquel contra quien se promueva un proceso civil, con el cumplimiento de las formalidades legales, con razón o sin ella, como también quien interviene ya voluntariamente, ya a instancia de parte o de orden judicial».

Por ello, insistimos, hay terceros en el sentido procesal, que son parte en el aspecto material mientras se mantengan ausentes del proceso. Son parte en el sentido material pero no en sentido procesal.

Menos frecuente será el caso contrario, en el que la parte procesal no lo sea en el aspecto material. Generalmente deberán coincidir, dado que si la parte procesal no lo es en sentido material, es decir, si no es sujeto de la relación jurídica discutida, la sentencia de fondo será desfavorable a sus intereses.

\subsection{EI tercero}

Por tercero se entiende generalmente a aquella persona ajena a la relación jurídica contemplada. Sin embargo, cuando estamos frente a la intervención de terceros en el proceso, debemos tener presente que el tercero facultado para intervenir en el juicio debe estar necesariamente vinculado a la materia de la litis por un interés directo o indirecto, propio o ajeno, concurrente o excluyente respecto de las partes originarias, pues de otra manera no será admisible su intervención.

Ello significa que el tercero, si bien es formalmente ajeno al proceso, no debe serlo respecto de la relación sustancial, en la cual debe tener un mínimo grado de interés. Así, el tercero, siéndolo en el aspecto procesal, podrá ser parte material; o no siéndolo, ser sujeto de una relación sustancial con una de las partes procesales, relación que se verá afectada por la decisión que se dicte en el proceso en el que pretende intervenir.

Obviamente, lo expuesto no implica la inexistencia de terceros totalmente ajenos y extraños a la relación sustancial.

Lo que sucede es que éstos siempre tendrán la condición de terceros, pues jamás podrán solicitar y conseguir que se admita su participación en el proceso, por cuanto carecen de legitimación para ello, carecen del denomi- 
nado «interés jurídico relevante». En síntesis, es justamente este interés directo o indirecto del tercero, esta vinculación, lo que lo legitima para poder ingresar en el proceso.

En base a este grado de interés o vinculación, podemos concluir que existen tres clases de terceros intervinientes:

a) Aquellos que aducen un derecho propio, independiente y oponible al que pretenden las partes, y que tienen la característica de ser principales y autónomos. Se les puede dividir a su vez en dos subcategorías:

a.1. La primera, cuando intervienen en el proceso oponiendo un derecho propio pero no excluyente del invocado por el demandante, porque no pretenden ser titulares del derecho que éste reclama, sino de otro derecho contra el demandado que puede coexistir con el del demandante. Como ejemplo tenemos la tercería de derecho preferente prevista en el tercer párrafo del artículo 100 del Código Procesal Civil, en la que el tercero interviniente no busca la exclusión del derecho del demandante, sino que persigue que su crédito sea cubierto con el producto de la ejecución forzada antes que el crédito del ejecutante.

a.2. La segunda subcategoría la constituyen aquellos que intervienen en el proceso con pretensiones incompatibles con las del demandante y del demandado, pues se busca excluir a ambos del derecho perseguido, del cual dichos terceros se reclaman únicos titulares. Éste es el caso a que se refiere el artículo 99 del Código Procesal, por ejemplo cuando el heredero de mejor derecho concurre a un juicio entre herederos putativos, reclamando la herencia para sí.

b) Aquellos que pretenden un derecho propio vinculado al proceso y que se discute en él, y que es similar, en todo o en parte, al derecho afirmado por una de las partes en el proceso. Su situación es autónoma e independiente, pero no opuesta sino concordante con la de la parte original. Éstos son los llamados intervinientes litisconsorciales o litisconsortes sucesivos, cuya intervención está regulada en el artículo 98 del código adjetivo.

c) Por último, existen aquellos terceros que no reclaman un derecho propio para que sobre él se dé pronunciamiento en el juicio en que intervienen, pero que sí tienen un interés personal en la suerte de la pretensión de 
una de las partes, con miras a evitar efectos reflejos o secundarios que puedan serles perjudiciales. Es así que concurren al proceso exclusivamente para ayudar a la parte en la lucha procesal, motivo por el cual su participación es secundaria o accesoria. Es el caso previsto en el artículo 97 de la ley procesal.

\section{La intervención voluntaria}

Como su nombre lo indica, esta intervención se producirá como consecuencia de la voluntad del tercero, quien por determinación propia y libre decidirá participar e intentar su admisión en un proceso vigente entre otras personas. Se subdivide en intervención coadyuvante, intervención litisconsorcial e intervención excluyente.

\subsection{Intervención coadyuvante}

Como quedó esbozado anteriormente, en la intervención coadyuvante o adhesiva, a diferencia de lo que sucede en los otros tipos de intervención, el tercero pretende incorporarse al proceso para colaborar con una de las partes en litigio, no para defender un derecho propio discutido en el proceso, sino que su legitimación deriva únicamente del interés que tiene en evitar los efectos reflejos o secundarios de la sentencia, que pueden indirectamente repercutir en su relación con la parte a la que ayuda.

Es así que la intervención coadyuvante tiene la calidad de accesoria o secundaria, puesto que con ella no se presenta pretensión alguna propia del interviniente, sino que se limita a sostener razones de alguna de las partes contra la otra, ayudándole a sostener su derecho en juicio. Sobre la intervención adhesiva o coadyuvante y su razón de ser y fundamento, Ugo Rocco ${ }^{10}$ nos dice lo siguiente: «Mediante la intervención adherente, el tercero aspira, en efecto, únicamente a aliarse con una de las partes en litigio, a fin de ayudarla a hacer valer sus derechos contra la otra, y hacer valer un

10 Rocco, Ugo, Tratado de Derecho procesal civil, Editorial Temis, Bogotá, 1976, volumen II, pág. 135. 
interés propio, y no un derecho propio, por cuanto la victoria o la derrota de la parte ayudada implica correlativamente una ventaja o una desventaja tales que repercutan en una relación jurídica de la que es sujeto el interviniente».

Como se aprecia, la participación del tercero se sustenta tan sólo en una vinculación de éste con la parte ayudada, vinculación que corresponde a una relación jurídica sustantiva diferente de la que subyace a la relación jurídica procesal que vincula al ayudado con su contraparte en el proceso. Devis Echandía ${ }^{11}$ define esta circunstancia de la siguiente manera: «E1 coadyuvante puede ser, por consiguiente, ajeno a la relación sustancial debatida en el proceso por su coadyuvado (por ejemplo: no reclama ningún derecho en el inmueble cuya propiedad se discute), pero existirá otra relación sustancial entre ellos, que puede resultar afectada con la decisión que sobre la primera se adopte en el proceso (una relación de crédito, que no podrá satisfacer si el coadyuvado pierde el pleito; o una relación de parentesco que podrá lesionarse moral y socialmente, en el mismo supuesto, como la de padres en el proceso de divorcio de los hijos menores no habilitados de edad). El coadyuvante no es cotitular de la misma pretensión del coadyuvado, porque entonces tendría una pretensión propia en ese proceso y sería litisconsorte; sino titular de la suya propia y por esto, aun cuando no está legitimado para demandar respecto a la relación sustancial de aquél, sólo lo está para intervenir en el proceso que inició su coadyuvado o se sigue contra éste. $=$ Se trata de una legitimación menos plena, que sin facultarlo para demandar la pretensión de su coadyuvado, sí lo autoriza para coadyuvarla o defenderla en el proceso iniciado por éste o contra éste».

Ahora bien, el problema surge al momento de determinar cuándo existe el interés que legitime la intervención coayuvante del tercero. En la intervención principal excluyente y en la litis consorcial, el interviniente es titular de un derecho conexo o semejante al discutido en el proceso, reduciéndose la legitimación en causa, en dichos casos, a la titularidad del derecho alegado. En la intervención coadyuvante o adhesiva, por el contrario, el interés del interviniente radica precisamente en la desconexión entre la relación jurídica deducida en el proceso y la existente entre el interviniente y la parte a la que se adhiere. Por ello, resultará imprescindible examinar caso

11 Devis Echandía, Hernando, Compendio de Derecho procesal civil, Editorial ABC, Bogotá, 1985, tomo I, pág. 353. 
por caso el interés aducido, para determinar cuándo éste otorga al tercero la facultad extraordinaria de intervenir en el proceso como coadyuvante.

Este interés del interviniente derivará, en la mayoría de los casos, de un perjuicio material económico que resultará de la derrota en el proceso de la parte ayudada. Algunos autores niegan la admisión de la intervención adhesiva sustentada en un interés moral, de amistad o parentesco, limitando la legitimación de esta intervención a un contenido material que afecte una relación jurídica propia del interviniente. Sin embargo, Devis Echandía ${ }^{12}$, citando a Chiovenda, Carnelutti, Rocco y Alsina, sostiene que la legitimación del coadyuvante puede estar sustentada en un interés jurídicamente tutelado que puede ser patrimonial, moral o familiar cuya satisfacción o realización dependan de los resultados de ese proceso, en vista de una relación jurídica que exista entre el tercero interviniente y una de las partes. A pesar de lo expuesto, consideramos que serán muy escasas las intervenciones adhesivas sustentadas en intereses no patrimoniales, debiendo el juez, en todo caso, como lo manifestáramos en líneas precedentes, hacer una aplicación restrictiva de la institución bajo estudio.

El interés del coadyuvante debe ser actual y no futuro. Del mismo modo, tampoco puede considerarse suficiente para la intervención adhesiva el interés en obtener una sentencia justa o crear un precedente judicial.

El artículo 97 del Código Procesal Civil peruano, que regula la intervención adhesiva o coadyuvante, autoriza la intervención del tercero en el proceso cuando tenga con la parte ayudada una relación jurídica a la que, si bien no se extenderán los efectos de la sentencia que se dicte en el proceso, sí se verá afectada desfavorablemente si la parte ayudada es vencida. En consecuencia, resulta claro que lo que en definitiva defiende el tercero es un interés propio, evitando que los efectos de una sentencia desfavorable al coadyuvado se reflejen en la relación jurídica que el tercero tiene con éste. Sobre esta condición constituida por el interés propio del tercero, Calamandrei ${ }^{13}$ expresa que debe fundarse en que «aunque en el proceso en que interviene el tercero se discuta, no un derecho suyo, sino solamente el

12 Devis Echandía, Hernando, op. cit., pág. 353.

13 Calamandrei, Piero, Derecho procesal civil, Ediciones Jurídicas Europa-América, Buenos Aires, 1973, tomo II, pág. 32. 
derecho de la parte ayudada, al cual el tercero es extraño; sin embargo sabe el tercero, que si en ese proceso sale vencida la parte ayudada, su derrota vendría a repercutir indirectamente sobre dicho tercero, evitándole para el futuro la posibilidad de ejercer un derecho suyo en las mismas condiciones favorables en que hubiera podido ejercerlo de haber salido victoriosa la parte por él ayudada».

En cuanto a la posición procesal del interviniente adhesivo como parte, éste, a diferencia del interviniente litisconsorte que hubiera podido ser parte originaria en el proceso, como demandante o demandado, sólo puede intervenir cuando existe un proceso pendiente entre otros, pues el interviniente litisconsorte defiende derechos propios y el interviniente coadyuvante va a la defensa de derechos de otros. Ciertamente que, como acabamos de expresar, esta defensa la hace en su propio interés, para proteger su derecho que indirectamente se ve amenazado. Pero su propio derecho queda en una posición secundaria, a diferencia del interviniente litisconsorcial, cuyo derecho es el mismo que el discutido en proceso.

Esta posición secundaria del derecho del interviniente en relación al derecho de la parte, discutido en el proceso, conduce a afirmar que el interviniente coadyuvante es en el proceso una parte secundaria o accesoria, frente a las partes principales que son el demandante y el demandado.

En la doctrina italiana, el interviniente es considerado como parte, mientras que la doctrina alemana le niega tal condición. Sobre el particular, nosotros coincidimos con la primera, y hacemos nuestras las palabras de Podetti ${ }^{14}$ en el sentido de que es erróneo sostener que ciertas figuras de las tercerías (ad adyuvandum) no dan al tercerista el carácter de parte o sujeto procesal, ya que siempre y en todos los supuestos el interviniente es sujeto del proceso.

En nuestra opinión, no existe duda de que el interviniente es parte, pues de otra forma no se comprendería su intervención en el proceso. Si por parte entendemos a la persona que pide o frente a la que se pide una de-

14 Podetti, Ramiro; Derecho procesal civil y comercial y laboral, Ediar S. A. Editores, Buenos Aires, 1973, tomo III, pág. 33. 
terminada actuación judicial, el interviniente será parte en cuanto efectúa diversas peticiones en el curso del proceso. Sobre el asunto, Devis Echandía ${ }^{15}$ nos explica: «El coadyuvante es parte en el proceso, aunque de condición secundaria o accesoria, ya que tiene el derecho de interponer recursos, a pedir pruebas, a proponer nulidades y actúa hasta la terminación del proceso; además, las limitaciones a que está sujeto en su actividad procesal (...), no afectan su calidad de parte, pues sirven apenas para reducirlas a la de parte accesoria o secundaria».

Problema distinto será el de analizar si el tercero coadyuvante es parte en sentido material, lo que evidentemente no es, pues precisamente las características de esta intervención derivan de la desvinculación del interviniente respecto del objeto del proceso. La actividad del interviniente coadyuvante es una actividad procesal pura, en cuanto se desarrolla y agota en el proceso, sin que le correspondan otros poderes que los estrictamente procesales, estándole prohibida toda disposición sobre el objeto del proceso y hallándose subordinada su posición a la de la parte principal.

El artículo 97 del Código Procesal Civil dispone que: «El coadyuvante puede realizar los actos procesales que no estén en oposición a la parte que ayuda y no impliquen disposición del derecho discutido». Ello implica que podrá efectuar toda clase de alegaciones, oponer excepciones, proponer tachas y oposiciones, y desistirse de su intervención. Ahora bien, todas estas posibles actitudes del coadyuvante no pueden contradecir la actividad desplegada por la parte ayudada. El coadyuvante podrá actuar para suplir o complementar la actividad del coadyuvado, pero nunca para ir contra la voluntad de éste. En este orden de ideas, si coadyuva al demandante no podrá por ejemplo oponerse al desistimiento de éste, ni aceptar las excepciones propuestas por el demandado cuando hayan sido rechazadas por el demandante, o éste guarde silencio respecto de ellas. Si coadyuva al demandado, no podrá confesar los hechos invocados por el demandante, ni allanarse a la demanda, ni oponerse a ella si el demandado la acepta allanándose. En este último caso, podrá solicitar al juez declare improcedente el allanamiento por presunción de existencia de fraude o dolo procesal conforme al inciso $7 \mathrm{del}$ artículo 332 del Código Procesal Civil. En síntesis, el coadyuvante podrá realizar los actos procesales que le corresponden a la parte principal, con las

15 Devis Echandia, Hernando, ob. cit., pág. 356. 
limitaciones expuestas, las que se sustentan en impedir que el coadyuvante realice actividades que impliquen una contradicción con la actitud asumida por la parte ayudada. Puede en todo caso el coadyuvante suplir el silencio o el abandono de la parte principal.

Dada la condición de accesoriedad del coadyuvante y que sus actos se estiman en favor de la parte ayudada, aquél no puede ser testigo. Además, tendrá siempre un interés indirecto en el resultado del proceso, lo que lo hará incurrir en la causal de prohibición prevista en el inciso 4 del artículo 229 del Código Procesal Civil. Tampoco podrá brindar declaración de parte, pues éste es un medio probatorio que busca la confesión de hechos que perjudiquen a la parte deponente, o en todo caso de hechos con consecuencias jurídicas a cargo de ella. Considerando que la declaración del coadyuvante no acarrearía consecuencias jurídicas a su cargo pues la sentencia no le afectará de manera directa, no se da entonces el supuesto fundamental del medio probatorio. En todo caso, respecto de quien su declaración de parte surtirá efecto será del coadyuvado. Pero debemos tener presente que todos los actos del interviniente se estiman en favor de la parte ayudada, por lo que la declaración de parte de acuerdo a su naturaleza atenta frontalmente contra la razón de ser de la intervención coadyuvante.

En cuanto a la apelación, la doctrina es unánime en el sentido de que el interviniente coadyuvante puede apelar de la sentencia, pues éste es un simple acto de defensa que puede ser interpuesto por el interviniente con independencia de la parte principal. Sin embargo, si ésta renuncia expresamente al recurso de apelación (por ejemplo en el caso de la casación por salto prevista en el artículo 389 del Código Procesal Civil), la apelación del interviniente quedará sin valor, por carecer de sentido. Recordemos que el interviniente coadyuvante puede actuar mientras los efectos de su actuación no vayan contra la voluntad expresa de la parte principal ayudada.

De otro lado, en cuanto a los efectos de la sentencia, en la intervención adhesiva éstos son totalmente diferentes a los que se dan en las demás clases de intervención, en las que el interviniente, luego que accede al proceso, se ve afectado directamente por ella. En la intervención coadyuvante la sentencia no produce en sus efectos obligatorios repercusión alguna sobre el interviniente, abriendo únicamente la posibilidad de que tales efectos se produzcan. En efecto, mientras que en la intervención principal (excluyente o litisconsorcial) la sentencia es susceptible de perjudicar directamente al 
tercero interviniente, en la coadyuvante la sentencia sólo es susceptible de ocasionar perjuicios en potencia, requiriendo de otro proceso en el que dicha sentencia constituirá uno de los presupuestos de la consecuencia jurídica que se pretenda aplicar en el curso de ese nuevo proceso. Ahora bien, de todos modos la sentencia tendrá un efecto vinculante respecto del coadyuvante, en tanto éste no podrá discutir en un nuevo proceso sus conclusiones.

Respecto de la oportunidad en que puede admitirse la intervención coadyuvante, el Código Procesal Civil en el segundo párrafo del artículo 97 dispone que puede suceder incluso durante el trámite en segunda instancia. Debemos entender que cuando la norma expresa «durante el trámite» significa que la intervención podrá ser admitida hasta antes que se dicte sentencia en segunda instancia. Para reforzar esta afirmación recurrimos nuevamente a Devis Echandía ${ }^{16}$, quien como presupuesto de la intervención coadyuvante reconoce «que la sentencia no haya sido dictada si no tiene recursos, o no haya quedado ejecutoriada si los tiene; pero después de dictada la sentencia de segunda instancia no puede proponerse coadyuvancia para interponer casación, porque este recurso extraordinario sólo pueden proponerlo quienes eran partes cuando se dictó la sentencia».

El nuevo Código Procesal en el artículo 101 establece la forma de la intervención, la que debe cumplir con la formalidad prevista para la demanda y contener los fundamentos que configuran el interés que legitima la intervención, acompañándose todos los medios probatorios destinados a acreditar dicho interés. La procedencia o denegatoria del pedido de intervención la decidirá el juez inaudita pars, es decir, de plano y sin oír a las partes originarias. Los intervinientes se incorporan al proceso en el estado en que éste se halle al momento en que su intervención es admitida.

A manera de referencia, a continuación indicamos algunos casos en que, según Serra Domínguez ${ }^{17}$, se acostumbra admitir la intervención adhesiva:

16 Devis Echandía, Hernando, ob. cit., pág. 353.

17 Serra Domfnguez, Manuel, Estudios de Derecho procesal civil, Ediciones Ariel, Barcelona, 1969, pág. 229. 
a) Cuando el derecho discutido en el proceso sea el presupuesto esencial para la subsistencia de determinada relación jurídica entre el tercero y cualquiera de las partes. Por ejemplo, la intervención del subarrendatario en el proceso seguido contra el arrendatario por el propietario, o la intervención del subarrendatario en el juicio seguido entre el pretendiente de la cosa arrendada y el arrendador. En ambos casos, la pérdida del proceso para el transmitente lleva aparejada la desaparición de uno de los presupuestos del derecho del interviniente. La sentencia no se pronunciaría respecto del subarrendatario, pero al destruir la titularidad del arrendador desaparecerá el título que legitima la posesión de la cosa, y posibilitará que en un proceso posterior pueda ser desposeído el subarrendatario.

b) Intervención de personas interesadas en que no disminuya el patrimonio de uno de los litigantes o en que aumente dicho patrimonio. Como ejemplo tenemos la intervención del fiador en el proceso seguido contra el deudor para el pago de una deuda, aunque ésta no sea la misma que corresponde a la fianza, pues la derrota del deudor puede hacer inútil el beneficio de excusión; o la intervención de los socios de una sociedad mercantil en los procesos seguidos en reclamación de deudas de la sociedad. En los casos mencionados, el interviniente tiene interés en la victoria de la parte principal, en cuanto la derrota de ésta disminuirá su garantía y podrá eventualmente hacerle perder el crédito o responder de otras deudas del vencido, o incluso de la propia deuda, en todo o en parte.

c) Intervención de aquellas personas que deberían indemnizar los perjuicios derivados de la sentencia en virtud de una relación contractual. Por ejemplo, intervención del asegurador en el juicio iniciado contra el asegurado por daños y perjuicios a una tercera persona.

d) Intervención de aquellos que pueden ser demandados en un proceso ulterior para indemnizar al vencido por los perjuicios derivados de la derrota que les son imputables. Por ejemplo, la intervención del mandatario en el juicio seguido contra el mandante por terceros que exigen responsabilidad en virtud de actos realizados por el mandatario contra las instrucciones del mandante; o intervención de los responsables directos (dependiente, conductor del vehículo) en los procesos sobre reclamación de daños dirigidos contra el responsable por culpa in vigilando (empleador, propietario del vehículo), casos en los que la negligencia del tercero interviniente le obligará 
a éste a indemnizar en un proceso ulterior, si es que es declarada dicha negligencia en el proceso en el que desea intervenir.

Los casos propuestos en los incisos c) y d) precedentes, además de dar la posibilidad al tercero de intervenir voluntariamente, constituyen claros supuestos para la procedencia de lo que en doctrina se denomina llamamiento en garantía y que es regulado en el Código Procesal Civil, en su artículo 104 , como aseguramiento de pretensión futura, en virtud del cual será el demandado quien exija el emplazamiento del tercero, para que, en el mismo proceso, se resuelva tanto la pretensión del demandante frente al demandado, como la de éste frente al tercero. Sobre esta forma de intervención forzada trataremos más adelante ${ }^{18}$.

\subsection{Intervención litisconsorcial}

La intervención litisconsorcial es aquella en la que un tercero interviene en un proceso para defender derechos propios que se discuten en el proceso, y que son similares, en todo o en parte, a los afirmados por una de las partes en litigio. Tiene por objeto evitar la extensión de los efectos de la sentencia.

Estructuralmente, la intervención litisconsorcial no modifica objetivamente el proceso, pues se produce simplemente una modificación en cuanto a los sujetos procesales, que se amplían, por cuanto a una de las partes se incorpora una persona más.

En la intervención litisconsorcial o litisconsorcio sucesivo, la pretensión del interviniente es propia, pero jurídicamente conexa y paralela con la de la parte consorcial (demandante o demandada), por emanar de la misma causa jurídica o título, o por ser el interviniente titular de la misma relación jurídica. Así, la suerte de éste y de la parte consorcial debe ser común y la declaración judicial que sobre ellas recaiga debe ser la misma.

En la doctrina procesal se encuentra que muchas veces se cita como ejemplo de intervención litisconsorcial el caso de la solidaridad de deudores o acreedores. Sin embargo, en nuestro medio ello no es así, por cuanto el

18 Infra, 3.2. 
artículo 1193 del Código Civil establece que la sentencia pronunciada en juicio seguido entre el acreedor y uno de los deudores solidarios, o entre el deudor y uno de los acreedores solidarios, no surte efecto entre los demás deudores o acreedores, respectivamente. De este modo, no se presenta el supuesto fundamental para la intervención litisconsorcial exigido por el propio artículo 98 del Código Procesal Civil, es decir, que los efectos de la sentencia se extiendan al interviniente. En tal virtud, el deudor o acreedor solidario de una de las partes no estará legitimado para intervenir litisconsorcialmente, pues si bien será cotitular del derecho que se discute, la sentencia que se dicte no extenderá sus efectos respecto de él, careciendo en consecuencia de interés para la intervención litisconsorcial. En todo caso, el deudor o acreedor solidario podrá intervenir adhesivamente para defender su propio interés, a fin de oponer en posterior proceso la sentencia dictada en el que intervino, conforme al segundo párrafo del mencionado artículo 1193 del Código Civil.

Uno de los casos en que podrá producirse una intervención litisconsorcial será la intervención de un copropietario en el juicio de reivindicación iniciado por otro copropietario. En este supuesto, si el primero no concurre al proceso iniciado por el segundo, la sentencia que se dicte sí le será oponible, pues la ley faculta para que cualquiera de los copropietarios pueda interponer la demanda, cuyas consecuencias afectarán a los demás condóminos del bien. Lo expuesto se desprende de lo dispuesto por el artículo 979 del Código Civil.

La condición para la intervención litisconsorcial, además que los efectos de la sentencia puedan extenderse al interviniente, es que éste hubiera podido ser parte originaria, es decir, que podría haber formulado la demanda o haber sido demandado, en su caso. Su distinción respecto de las partes originarias radica únicamente en el momento de su intervención: original en el caso de las partes iniciales y sucesiva en el caso del interviniente. Ambas partes tienen plena legitimación, tanto sustancial como procesal, legitimación que tiene carácter autónomo.

Tienen asimismo igualdad en su posición procesal, no existiendo ninguna relación de dependencia, como sí ocurre en la intervención coadyuvante, encontrándose en una misma posición frente a la sentencia, que debe ser una y común para ambas. La autonomía procesal existente entre el interviniente y la parte litisconsorcial significa que, si bien pueden uti- 
lizar iguales medios de defensa y proponer los mismos medios probatorios, pueden también observar, cada una, una conducta procesal diferente, por cauces diversos y hasta opuestos.

De acuerdo a la naturaleza de la intervención litisconsorcial, Serra Domíngue $\mathrm{z}^{19}$ obtiene las siguientes conclusiones:

a) Los actos realizados con pleno éxito por una de las partes aprovecha a la otra. El litisconsorte diligente aprovecha al litisconsorte negligente.

b) Como consecuencia de lo anterior, cualquier acto realizado por uno de los litisconsortes dentro del plazo, aprovecha a los que no lo han verificado, y pueden adherirse con posterioridad.

c) Cuando el primer litisconsorte retira la demanda o desiste de la apelación, el interviniente litisconsorcial continuará con el proceso.

d) Los actos realizados por uno de los litisconsortes no pueden perjudicar a los demás.

Acerca del momento de la intervención litisconsorcial, ésta puede producirse en cualquier estado del proceso, incluso durante el trámite en segunda instancia. El momento límite es hasta antes que se dicte sentencia en segunda instancia. Así fluye también de lo expuesto en el artículo 98 del Código Procesal, cuando indica que la intervención litisconsorcial «puede ocurrir incluso durante el trámite en segunda instancia». Obviamente el interviniente tomará el proceso en el estado en que se encuentre, ateniéndose a las consecuencias desfavorables que pueden derivarse de las oportunidades procesales ya precluidas.

Es de notar que el hecho de que se permita tanto la intervención del tercero coadyuvante como litisconsorcial incluso durante el trámite en segunda instancia, no causa mayor inconveniente, considerando además que no se contradice el principio de la instancia plural. En efecto, como el interviniente coadyuvante y el interviniente litisconsorcial no introducen al proceso una pretensión nueva y diferente de la que ya existe en él, no lo

19 Serra Domínguez, Manuel, op. cit., pág. 240. 
modifican objetivamente, por lo tanto, el juzgador en segunda instancia resolverá, objetivamente, respecto de las mismas pretensiones que fueron objeto de pronunciamiento en la instancia anterior.

Por último, consideramos que resulta oportuno distinguir entre la intervención litisconsorcial voluntaria materia de análisis, referida al litisconsorcio facultativo previsto en el artículo 94 del Código Procesal Civil, y el litisconsorcio necesario regulado por los artículos 93 y 95 del mismo código. El litisconsorte facultativo puede intervenir en el proceso si voluntariamente así lo decide, y su ausencia no impedirá la formación de una válida relación procesal entre las partes originarias ni la expedición de una sentencia eficaz sobre el fondo del asunto, la que extenderá sus efectos respecto de él. Sin embargo el litisconsorte necesario debe participar en el proceso, y su ausencia impedirá la correcta formación de la relación procesal. Por ello el juez, si advierte la existencia de un litisconsorcio necesario en la parte demandada, está en la obligación de integrar la relación procesal emplazando al litisconsorte necesario, sin cuya participación en el proceso no podrá dictarse sentencia sobre el fondo. Si el litisconsorcio necesario existe en la parte demandante y no se ha conformado, la demanda será rechazada por improcedente al carecer el demandante de legitimidad para obrar, al amparo del inciso 1 del artículo 427 del Código Procesal, o en todo caso, si la situación no es advertida por el juez, podrá el demandado deducir la excepción correspondiente (falta de legitimidad para obrar en el demandante) prevista en el inciso 6 del artículo 446 del mismo código.

\subsection{Intervención excluyente}

También llamada intervención de tercerista o de tercero autónomo.

Anteriormente, en el punto 1.3 indicamos que a los intervinientes principales excluyentes podíamos subdividirlos en dos subcategorías: la primera, aquella en la que el sujeto interviene en el proceso con una pretensión propia contra el demandado, respecto del mismo bien materia de la litis, oponible al mismo tiempo al demandante, pero sin intención de excluirlo; y la segunda, aquella en la que el sujeto interviene con una pretensión propia incompatible con las del demandante y las del demandado, buscando excluir 
a ambos del derecho discutido, del que se declara titular, total o parcialmente.

La subdivisión mencionada es necesaria para determinar las dos diferentes posturas que puede adoptar el interviniente principal frente a las pretensiones del demandante, pues su posición ante el demandado siempre será excluyente.

En la primera subcategoría podemos incorporar a la intervención excluyente de derecho preferente en un proceso cautelar, que está regulada por el artículo 100 del Código Procesal Civil. En ella el interviniente actúa concurriendo con el demandante a pesar de aducir un derecho con distinta causa pretendi, que le es oponible, y que será contrario a los intereses de dicho demandante en cuanto puede disminuir su derecho o la satisfacción de su crédito en virtud de la concurrencia del interviniente. En este caso, aunque el demandante resulte insatisfecho en su pretensión principal de pago total como consecuencia del derecho alegado por el interviniente, ello es simplemente el resultado de la actuación de éste, pues al intervenir en el proceso cautelar formulando su pretensión no lo hizo negando el derecho del demandante a cautelar su crédito afectando determinado bien, pues el interviniente no lo discute. El interviniente sólo pretende que se reconozca su derecho a que su crédito sea satisfecho de manera preferente al del demandante titular de la medida.

La segunda subcategoría implica una postura completamente diferente por parte del interviniente, pues éste busca excluir total o parcialmente al demandante, ya que pretende ser declarado titular del derecho discutido, total o parcialmente. Éste es el supuesto previsto en el artículo 99 del Código Procesal Civil, y que sería aplicable al ejemplo siguiente: Eduardo demando a Julia reclamando la propiedad de un bien, del que Julia se considera propietaria. Durante el proceso aparece Raúl, quien solicita su admisión pues afirma ser el titular del dominio sobre el indicado bien.

En cuanto a la intervención excluyente de propiedad prevista en el artículo 100 del mismo código procesal, somos de la opinión que también está dentro de esta segunda subcategoría, ya que el tercero interviene en el proceso cautelar con el ánimo de excluir al demandante de su pretensión cautelar (afectar determinado bien), pues afirma ser el propietario del bien 
indebidamente afectado. A diferencia de la intervención de derecho preferente, en la que el interviniente no discutía el derecho del demandante a afectar el bien, sino que se limitaba a sostener que era titular de un mejor derecho que el del actor, el interviniente excluyente de propiedad sí discute el derecho del demandante de afectar el bien, pues sostiene que éste no es del demandado sino suyo.

Con vista al nuevo Código Procesal Civil, están reguladas las siguientes intervenciones voluntarias excluyentes:

a) La intervención excluyente principal, por la que el tercero pretende, en todo o en parte, ser declarado titular del derecho discutido en el proceso, por lo que formula su exigencia contra demandante y demandado para que se resuelva ésta en el mismo proceso.

b) Intervención excluyente de propiedad o de derecho preferente, en la que el tercero interviene no para oponer una pretensión en el proceso principal, sino en el proceso cautelar instaurado para tomar medidas preventivas a fin de evitar el peligro en la demora del proceso principal. Una vez ejecutada la medida cautelar, si ésta ha recaído en bien de propiedad de un tercero, o respecto del cual éste tiene un derecho preferente al del actor, dicho tercero podrá intervenir en el proceso cautelar a fin de hacer prevalecer su derecho sobre el bien afectado. Como es evidente, el tercero no interviene en el proceso principal, pues no invoca ningún derecho respecto de la pretensión principal discutida en él, sino que su intervención se ve limitada al proceso cautelar y busca oponerse a los derechos que las partes originarias pretenden en dicho proceso.

En todos los casos el interviniente no se limita a una pasiva oposición a las pretensiones del demandante, sino que concurre al proceso (principal o cautelar) alegando pretensiones propias, a fin de obtener una declaración judicial en ese mismo proceso, que las ampare. Por ello se le denomina también demandante sucesivo, dirigiendo su pretensión contra el demandante y demandado iniciales, con quienes entra en litiio ya sea persiguiendo excluir al demandante inicial o simplemente pretendiendo vincularlo u obligarlo a la decisión que se dicte en favor del interviniente.

No existe por lo tanto la comunidad de suertes que se produce en la intervención litisconsorcial, pues la pretensión que introduce el interviniente 
es propia y sobre todo independiente, siendo su título también distinto, por lo que la suerte que corra dicha pretensión será por lo general también distinta a la de las pretensiones de las partes originarias. En otras palabras, el tercero introduce un nuevo litigio, sobre el que deberá resolverse en el mismo proceso.

Por ello se sostiene que este tipo de intervención produce la ampliación del objeto de la litis en el mismo proceso. Al respecto Carnelutti ${ }^{20}$ hace mención a diferentes litis, refiriéndose a la que existe entre demandante y demandado y a la que se presenta entre el interviniente y éstos, señalando expresamente que el interviniente excluyente «lleva consigo su litigio, cuya decisión en el mismo proceso pendiente pide al juez».

Ugo Rocco ${ }^{21}$ escribe sobre el tema afirmando que «con la intervención del tercero en el proceso pendiente se amplía un poco el tema de la controversia, en cuanto se presenta a juicio del juez la cuestión de saber cuál de los varios sujetos en la litis, que se afirman titulares de un derecho, debe considerarse como tal, con exclusión, por lo tanto, de los otros sujetos que reclaman la misma titularidad».

En cuanto a la legitimación del tercerista, ésta debe ser plena, tan completa como la que se requiere para la parte original. Por ello, el tercero interviniente excluyente principal a que se refiere el artículo 99 del Código Procesal Civil tiene la facultad, alternativamente a intervenir en el proceso, de iniciar un nuevo juicio con todos los derechos y facultades de tal circunstancia.

Cabe hacer presente una importante diferencia que existe entre la intervención excluyente y la intervención litisconsorcial, que consiste en que mientras esta última se puede dar entre el tercero interviniente y el demandante o el demandado, la primera es necesariamente opuesta y excluyente a la posición o defensa del demandado, frente al cual el tercero es un nuevo demandante, de modo tal que sus intereses no pueden coincidir nunca.

Es necesario que exista incompatibilidad entre la pretensión del

20 Carnelutti, Francesco, ob. cit., tomo I, pág. 105.

21 Rocco, Ugo, op. cit., volumen II, pág. 117. 
interviniente y la del demandante, y la del primero debe ser dirigida contra el demandado, con la aclaración hecha en líneas precedentes respecto de las dos distintas posiciones que puede aportar el tercerista respecto del demandante, es decir, que pretenda o no su exclusión en el objeto controvertido. Por ello, el presupuesto de la incompatibilidad de las pretensiones del tercerista y del demandante no conduce necesariamente a que éstas sean excluyentes. Asimismo, las dos pretensiones deben estar relacionadas con el objeto del juicio, en una relación de conexión entre las mismas, pero en contraste. Con quien siempre será excluyente la pretensión del interviniente será con el demandado.

Cuando el objeto litigioso versa sobre una cosa, en las pretensiones del demandante y del interviniente debe existir identidad respecto de ella, es decir, deben estar referidas a la misma cosa. Pero no es necesario que los derechos alegados sobre ella sean idénticos, bastando que sean incompatibles en relación con la cosa. Tampoco es suficiente que los derechos pretendidos sean distintos, pues, siéndolos, pueden no ser incompatibles, en cuyo caso no sería admisible la intervención excluyente. Por ello, no sería admisible la intervención principal excluyente del acreedor hipotecario en el juicio seguido sobre el dominio de un inmueble, pues la existencia de la hipoteca no es incompatible con la propiedad que alega el demandante.

En cuanto a la oportunidad de la intervención excluyente principal, ésta sólo puede producirse antes de la expedición de sentencia en primera instancia, a fin de que la nueva litis que se introduce cuente con la pluralidad de instancia que garantiza la administración de justicia. Debe considerarse que esta intervención, al introducir una pretension distinta e independiente, requiere de discusion, defensas y pruebas diferentes, respecto de la cual debe haber pronunciamiento judicial con la garantía de la instancia plural. Como indicamos anteriormente, esta exigencia no es aplicable a la intervención litisconsorcial, en la que la conexión y compatibilidad de las pretensiones hace que lo discutido y resuelto en primera instancia respecto de la parte consorcial originaria se aplique a la del interviniente. Lo mismo puede decirse respecto de la intervención coadyuvante.

En cuanto a la oportunidad de la intervención excluyente de propiedad, puede producirse en cualquier momento antes que se inicie el remate del bien, suspendiéndose la ejecución hasta que se decida sobre la propiedad del bien afectado, lo que se hará a través del proceso abreviado. El Código 
Procesal establece la posibilidad de suspender la medida cautelar sin demandar tercería, si se acredita la propiedad en el proceso cautelar, con título inscrito. Consideramos que en este caso, si es amparado el pedido, lo que sucederá, más que una suspensión de la medida, será un levantamiento de la misma, pues una suspensión implica que en algún momento ésta cesará, y en el caso comentado el levantamiento de la medida cautelar será definitivo en tanto ya quedó acreditado que el bien afectado no es propiedad del demandado.

La oportunidad para la intervención de derecho preferente es en cualquier momento antes que se realice el pago al acreedor, produciéndose la suspensión en dicho pago hasta que se resuelva sobre la preferencia, lo que sucederá mediante proceso abreviado.

Con relación a los efectos que produce la intervención excluyente podemos señalar que el interviniente adquiere la calidad de parte principal, en la posicion de demandante en el nuevo litigio que plantea, no en el proceso, porque en éste sigue teniéndola el primitivo demandante. En consecuencia, la relación jurídico procesal adquiere un nuevo sujeto, pero sin que por ello pierda su unidad, pues el proceso sigue siendo el mismo y único. Se da una ampliación en el proceso.

Siendo el interviniente excluyente parte principal desde el momento en que se acepta su intervención, cuenta con todos los derechos y facultades que tienen el demandante y el demandado, y puede ejercerlos en forma autónoma e individual, sin el consentimiento de ellos. Puede en consecuencia ofrecer pruebas, interponer medios impugnatorios $\mathrm{y}$, en definitiva, ejercer todos los derechos que le corresponden como parte principal que es.

Por último, en el proceso en que se ha dado la intervención se dictará una sola sentencia, para resolver, tanto la pretensión del demandante inicial, como la del interviniente y las defensas del demandado. Los efectos de esta sentencia son simultáneos e iguales para todos, en cuanto los vincula y obliga por igual.

\section{La intervención provocada}

En los casos que veremos a continuación, la intervención del tercero en el 
proceso no es producto de su voluntad, sino que se ve obligado a participar en él como consecuencia de un llamamiento formulado por el juez de la causa, ya sea porque su intervención ha sido solicitada por alguna de las partes a través de la denuncia civil, o porque el juez así lo ha ordenado de oficio.

Como lo expresa Devis Echandía ${ }^{22}$, la doctrina reconoce fundamentalmente cuatro clases de intervención provocada o forzosa: $1 .^{\circ}$ ) la denuncia del pleito, que se ha visto generalmente referida a casos de saneamiento por evicción; $2 .^{\circ}$ ) el llamamiento en garantía; $3 .^{\circ}$ ) la laudatio o nominatio autoris; $4 .^{\circ}$ ) el llamamiento del tercero pretendiente. A estos casos debe agregarse $5^{\circ}$ ) el llamamiente de oficio por fraude o colusión.

El Código Procesal Civil peruano regula, de manera expresa, las siguientes clases de intervención provocada u obligada: $1 .^{\circ}$ ) la denuncia civil, regulada en el artículo $102 ; 2 .^{\circ}$ ) el aseguramiento de pretensión futura, previsto en el artículo $104 ; 3 .^{\circ}$ ) el llamamiento posesorio a que se refiere el artículo 105, y $4 .^{\circ}$ ) el llamamiento en caso de fraude o colusión regulado en el artículo 106.

Salvo el caso del llamamiento del tercero pretendiente, nuestra ley procesal está legislando sobre todas las demás intervenciones provocadas a que se refiere la clasificación reconocida por la doctrina a la que hemos hecho referencia.

A continuación intentaremos aproximarnos a cada una de ellas.

\subsection{La denuncia civil}

También conocida como denuncia del pleito, litis denuntiatio, o su expresión germánica, streitverkundung.

Recurrimos nuevamente a Devis Echandía ${ }^{23}$, quien expresa que en el

22 Devis Echandía, Hernando, op. cit., pág. 359.

23 Devis Echandía, Hernando, op. cit., pág. 360. 
moderno derecho procesal la denuncia del pleito (o denuncia civil) y el llamamiento en garantía (o aseguramiento de pretensión futura) se consideran como una misma institución procesal, destinada a que las partes puedan solicitar el emplazamiento de un tercero que tiene con alguna de ellas una relación de garantía, ya sea real por corresponder al goce y disfrute de un derecho real que ha sido transferido, o personal cuando se trate de indemnizar perjuicios o restituir lo pagado. En el primer supuesto (garantía real) estará el caso del adquirente demandado en juicio de evicción, quien solicita la intervención del transferente. En el segundo supuesto (garantía personal) la obligación o responsabilidad del tercero puede tener un origen contractual, como por ejemplo el fiador solidario demandado que solicita la intervención del fiado como consecuencia del derecho que tiene a repetir contra éste; o extracontractual, en el caso del empleador demandado por daños causados por su dependiente, y que en ejercicio del derecho que tiene aquél para repetir contra éste solicita su intervención en el proceso.

De acuerdo a lo expuesto, denuncia civil y aseguramiento de pretensión futura constituirían una misma institución procesal, con lo cual cabría cuestionar la coexistencia de ambas en el Código peruano, en los artículos 102 y 104. Sin embargo, haciendo nuestra la explicación que de esta coexistencia hace el profesor Juan Monroy ${ }^{24}$, colocamos la denuncia civil como el género; y al aseguramiento de pretensión futura, al llamamiento posesorio, al llamamiento del tercero pretendiente, como especies del mismo género. En otras palabras, los llamamientos de terceros al pleito se harán mediante denuncia civil, la que puede estar sustentada en aseguramiento de pretensión futura, llamamiento posesorio, etcétera.

Ahora bien, de acuerdo a lo dispuesto en el artículo 102 del Código Procesal Civil, por la denuncia civil el demandado que considera que otra persona, además de él o en su lugar, tiene obligación o responsabilidad en el derecho discutido, denuncia a esta persona para que se le notifique el inicio del proceso. Acerca de esta norma, si partimos del supuesto que la denuncia civil es el género en torno a la cual giran las demás especies para lograr el llamamiento de terceros, consideramos que no ha debido limitar la posibilidad de denunciar sólo por parte del demandado, pues la especie

24 Monroy Gálvez,Juan, op. cit., pág. 55. 
aseguramiento de pretensión futura puede ser formulada por cualquiera de las partes, ya sea demandante o demandada. Por ello, el artículo 104 expresa: «La parte que considere...».

En cuanto a la oportunidad de la denuncia civil, si es formulada por el actor, debe hacerlo en el escrito de demanda; y si quien la plantea es el demandado, lo hará dentro del plazo que tiene para contestar la demanda. El denunciado a su vez podrá denunciar el pleito dentro del plazo que tiene para intervenir en él, el que de acuerdo al artículo 103 del Código peruano es de diez días.

Con relación al uso de la denuncia civil, de acuerdo al artículo 102 del Código Procesal Civil, procederá siempre que exista otra persona que, además del demandado o en su lugar, tenga alguna obligación o responsabilidad en el derecho discutido. Procederá particularmente en los casos correspondientes a las especies reguladas en los artículos 104 y 105 de las que nos ocuparemos más adelante.

Doctrinariamente la denuncia civil puede estar referida a todos aquellos casos en que de acuerdo a la ley sustantiva fluya un derecho que coloque a la parte en una situación tal que tenga interés para denunciar. Creemos que la redacción del artículo 102 del Código Procesal no colaborará a la admisión de algunas figuras de denuncia civil (p. ej, llamamiento del tercero pretendiente, donde el denunciado es aquella persona que formula al demandado la misma exigencia que se le reclama en el proceso), pues en el artículo citado se está limitando la denuncia a la formulada por parte del demandado, y sólo en cuanto éste considere que existe alguien que, además de él o en su lugar, tiene obligación o responsabilidad en el derecho discutido.

Respecto de los efectos procesales que producirá la denuncia, estarán constituidos por el emplazamiento al denunciado con las formalidades establecidas para la notificación con la demanda, la concesión de un plazo no mayor de diez días para que intervenga en el proceso, y la suspensión de éste durante el tiempo que transcurra entre la admisión de la denuncia y el emplazamiento al denunciado. Así lo expresa el artículo 103 del Código, según el cual, luego de emplazado el denunciado, es considerado como litisconsorte del denunciante, con las mismas facultades que éste.

Sustentado en el principio de economía procesal, el último párrafo del 
mencionado artículo 103 señala que, cuando sea pertinente, la sentencia resolverá sobre la relación sustancial entre el demandante y el demandado.

Resulta oportuno indicar que la denuncia civil puede constituir el medio para el demandado a fin de hacer conocer al juez la existencia de un litisconsorcio necesario, pues es obvio que el denunciado litisconsorte tiene obligación o responsabilidad en el derecho discutido, obligación o responsabilidad de tal naturaleza que imposibilita la expedición de una decisión válida sobre el fondo mientras este litisconsorte no sea emplazado.

\subsection{Aseguramiento de pretensión futura}

Este tipo de denuncia es conocido en doctrina como llamamiento en garantía.

Esta especie de denuncia civil existe para aquellos casos en que una de las partes, ya sea demandante o demandada, estime estar facultada para exigir de un tercero una indemnización por los daños y perjuicios derivados del proceso en que ella participa, o para repetir contra dicho tercero lo que tenga la parte que pagar en ejecución de sentencia. En tales supuestos, la parte puede solicitar el emplazamiento del tercero para que en el mismo proceso se decida acerca de la pretensión que tiene contra éste.

Resulta bastante claro el sustento de esta institución en el principio de economía procesal, evitando de esta manera, como sucedía antes de la vigencia del nuevo Código Procesal, la necesidad de que la parte en el proceso tuviera que esperar la culminación de éste para poder, posteriormente, intentar su pretensión contra el tercero en un posterior proceso. Asimismo, puede percibirse con bastante claridad que lo que busca la parte a través del mecanismo comentado es que el tercero denunciado quede condenado, en el mismo proceso, al cumplimiento de su prestación en favor del denunciante. No se persigue que el denunciado reemplace a la parte o que asuma conjuntamente con ella la condición de demandado, como sucede en el supuesto previsto en el artículo 102 del Código y que hemos comentado en el punto precedente.

Un ejemplo de la denuncia por aseguramiento de pretensión futura 
será la formulada por el propietario del automóvil, demandado en un proceso por indemnización por daños causados por el vehículo, pretendiendo el emplazamiento del conductor para que en el mismo proceso se resuelva sobre la pretensión que aquél tiene contra éste.

Como se aprecia, el denunciante en el aseguramiento de pretensión futura o llamado en garantía tiene la llamada «acción» de regresión o regresiva contra el denunciado, la que está condicionada a que el denunciante resulte vencido en el proceso. Para tal eventualidad, el denunciante solicita el emplazamiento del tercero, y así, si aquél es vencido, se le condenará a éste para que asuma las consecuencias de la derrota.

\subsection{Llamamiento posesorio}

Identificada también como intervención por laudatio o nominatio autoris, esta institución procesal regulada en el artículo 105 del Código Procesal se presenta cuando el demandante, en un proceso que contiene pretensiones posesorias, dirige éstas contra una persona que no es quien verdaderamente está en posesión del bien cuya restitución reclama, sino que es simplemente un tenedor del bien en nombre de otro. Esta circunstancia que coloca al proceso en una situación de carencia de legitimidad para obrar en el demandado, puede dar pie para que éste plantee la excepción correspondiente conforme al inciso 6 del artículo 446 del Código Procesal, o para que en la contestación a la demanda exprese esta situación indicando el nombre y domicilio del verdadero poseedor. Esta segunda opción constituye el llamamiento posesorio.

Como consecuencia del llamamiento posesorio, como sucederá en todo caso de denuncia civil, el proceso quedará suspendido desde que la denuncia sea admitida hasta el momento del emplazamiento al denunciado. Pero a diferencia de los otros casos de denuncia civil, en el llamamiento posesorio, si el denunciado comparece y reconoce su condición de poseedor, será emplazado con la demanda y reemplazará al demandado, quien quedará fuera de la relación procesal. Si por el contrario, el denunciado no comparece o haciéndolo niega ser poseedor, el proceso continuará con el demandado original y la sentencia será oponible a ambos. En este segundo caso el denunciado tendrá la calidad de litisconsorte del demandado. 
Lo expuesto resulta también aplicable cuando la demanda se dirige contra alguien atribuyéndole la condición de tenedor del bien sin serlo, pues la tenencia radica en otra persona.

Como es de notar, con esta denuncia se busca evitar la inútil continuación de un proceso que, al carecer de una «condición de la acción» como lo es la legitimidad para obrar en el demandado, podría ser declarado nulo. Así, la relación jurídico procesal se entablará con quien de acuerdo a la relación sustancial le corresponde estar en la posición de demandado. Como expusimos precedentemente, el demandado puede, alternativamente a la denuncia estudiada, deducir la excepción correspondiente, la que tendrá como efecto suspender el proceso hasta que la relación procesal se establezca entre las partes legitimadas dentro del plazo fijado por el juez.

Finalmente, haremos mención al apercibimiento aplicable contra el demandado en caso de encontrarse en el supuesto de la norma y abstenerse de denunciar, el que constará de una indemnización por los daños y perjuicios que su silencio cause al actor, más la multa a que se refiere el último párrafo del artículo 65 del Código Procesal.

\subsection{Llamamiento en caso de fraude o colusión}

La regulación de este instituto en el artículo 106 del Código Procesal otorga la facultad, exclusivamente al juez, para que en caso de presunción de fraude o colusión entre las partes llame al proceso a las personas que puedan resultar perjudicadas, a fin de que hagan valer sus derechos en él.

Alsina, citado por Augusto Ferrero ${ }^{25}$, nos indica que: «La intervención ordenada por el Juez es dispuesta no por el interés de parte, como en la anterior, sino del llamado. En ésta, el Juez actúa de orden público, llamando a quien él crea puede ser afectado por su decisión».

Será la conducta de las partes la que motivará al juez para que, pre-

25 Ferrero Costa, Augusto, «La intervención del tercero en el proceso», en $\mathrm{Li}$ bro homenaje a Mario Alzamora Valdez, Cultural Cuzco S.A. Editores, Lima, 1988, pág. 191. 
viendo las posibles consecuencias del resultado del proceso en el derecho del tercero, llame a éste para que participe en él defendiendo su derecho. No debe confundirse este llamamiento con la facultad otorgada al juez cuando existe litisconsorcio necesario, pues cuando éste se presenta existe la necesidad ineludible de la participación del litisconsorte en el proceso, sin la cual no puede conformarse válidamente la relación jurídico procesal. En el llamamiento por fraude o colusión la relación procesal está válidamente conformada, lo que sucede es que la conducta de las partes concordada con los eventuales efectos de la sentencia hacen presumir al juez que existe colusión entre ellas o intención de cometer fraude en perjuicio de un tercero.

Luego de la citación al tercero, éste intervendrá en el proceso y, en función de su grado de interés, se convertirá, creemos que en la generalidad de los casos, en un interviniente principal, ya sea excluyente o litisconsorcial.

En este punto resulta de interés analizar la oportunidad del llamamiento por fraude o colusión. De acuerdo a la norma procesal este llamamiento por parte del juez puede producirse en cualquier etapa del proceso, es decir, incluso durante el trámite en segunda instancia. Sin embargo cabe precisar que si como consecuencia del llamamiento al tercero éste tiene la posición de excluyente (entendido como pretensor, en todo o en parte del derecho discutido), no podrá resolverse su pretensión si es que su intervención se ha producido luego de la sentencia de primera instancia. Decimos esto porque, como lo hemos expuesto precedentemente ${ }^{26}$, la intervención excluyente principal sólo es admisible antes de la expedición en primera instancia, fundamentalmente para respetar el principio de instancia plural. Por lo tanto, el tercero deberá limitarse a procurar que el derecho discutido no le sea reconocido a ninguna de las partes originarias, para así, en ulterior proceso, intentar le sea reconocido a él.

Por último, se le otorga al juez la facultad de suspender el proceso por un plazo no mayor a treinta días.

26 Supra, 2.2. 


\section{Extromisión}

Así como el juez decidió la admisión de la intervención del tercero en el proceso, ya sea a pedido de éste, de alguna de las partes, o por decisión propia del magistrado, puede también el juez tomar la decisión de separar a este tercero del proceso cuando considere que el derecho o interés que legitimó su intervención ha desaparecido, o simplemente compruebe que nunca existió.

Como resulta evidente, esta institución persigue justamente el objetivo contrario a la intervención, es decir, apartar del proceso a aquella persona que estuvo participando en él como consecuencia de una intervención. Para ello debe basarse el juez en una de la dos consideraciones expuestas precedentemente, es decir, la desaparición del interés o el derecho que legitimó la intervención, o la posterior comprobación de la inexistencia de ese derecho o interés.

Estas consideraciones deben aparecer clara y expresamente sustentadas en la resolución que ordene la extromisión, no sólo en aplicación de la regla general sobre motivación de las resoluciones exigida en el inciso 3 del artículo 122 del Código Procesal, sino por la expresa disposición del artículo 107 del mismo código, según el cual la extromisión será ordenada por resolución «debidamente» motivada.

\section{Sucesión procesal}

La sucesión procesal implica un cambio en los sujetos de la relación procesal, reemplazándose por otra a la persona que en el proceso actuaba como parte. Como su nombre lo indica, ante ciertas circunstancias una persona sucede a otra que venía actuando como parte en el proceso, desapareciendo esta última de la escena procesal.

Por lo tanto, puede percibirse con claridad que la sucesion procesal no constituye ni es una modalidad de la intervención de terceros, pues en ésta el tercero participa en el proceso de manera adicional, coexistiendo con la parte originaria, mientras que en la sucesión procesal el sujeto que ingresa 
al proceso lo que hace es reemplazar, actuar en vez de la persona que estuvo conduciéndose como parte, ya sea demandante o demandada.

Esta sucesión en la relación procesal opera cuando se produce un cambio en la relación sustancial como consecuencia de la transmisión del derecho litigioso. Obviamente esta transmisión deberá haberse producido luego de instaurado el proceso, pues si sucedió antes, la persona que adquirió la condición de parte en la relación sustancial podrá serlo también procesalmente.

El artículo 108 del Código Procesal Civil recoge la figura de la sucesión procesal reconociendo, en una enumeración no limitativa, cuatro supuestos.

El primero es el de aquella persona que siendo parte en el proceso fallece, en cuyo caso sus herederos, que han adquirido el derecho discutido, lo sucederán en el proceso continuando con la actividad procesal. Si no lo hacen continuará el proceso con un curador procesal.

El segundo caso previsto por el Código es el de la extinción o la fusión de personas jurídicas. Si una persona jurídica que era parte en un proceso se extingue, y como consecuencia de ello el derecho litigioso es transmitido a uno de los socios en aplicación del artículo 378 de la ley general de Sociedades, será el socio quien, vía sucesión procesal, continúe actuando como parte en el proceso. Respecto de la fusión por absorción o incorporación, la sociedad incorporante sucederá a la incorporada al haber adquirido la totalidad de los derechos y obligaciones de esta última. En estos casos, al igual que en el del fallecimiento de la parte, si no comparecen los sucesores continuará el proceso con un curador procesal. Ello en razón de la desaparición del causante, lo que impediría la continuación de la relación procesal.

La tercera hipótesis es aquella de transmisión del derecho discutido por acto entre vivos, en cuyo caso el adquirente sucede en el proceso al transferente al haber perdido éste legitimidad para obrar.

El último supuesto previsto por el artículo citado es aquél en que el plazo del derecho discutido vence durante el proceso, en cuyo caso el sujeto que adquiere o recupera el derecho sucede en el proceso al que lo perdió. Un ejemplo claro es el del usufructuario que siendo perturbado en su pose- 
sión interpone interdicto de retener; sin embargo durante el proceso vence el plazo del usufructo, recuperando el propietario todos los atributos de la propiedad. Así, el propietario sucederá en el proceso al usufructuario, quien desaparecerá de la escena al haber perdido el derecho que legitimaba su actuación en el proceso.

\section{Conclusión}

La intervención del tercero en el proceso constituye un instituto procesal de transcendental importancia que, por primera vez, es regulado de manera sistemática en la legislación procesal nacional. Antes del Código Procesal vigente, además de las tercerías previstas para oponerse a los embargos, sólo existían algunas disposiciones dispersas que preveían de alguna manera la intervención del tercero, como por ejemplo los artículos 33 y 34 del Código de Procedimientos Civiles de 1912 que regulaban las facultades del representante del ausente para comparecer en procesos en los que éste «aparezca con un interés común o coadyuvante» al actor o al demandado; o la ley general de Sociedades, que en su artículo 146 permite la intervención coadyuvante del accionista que votó favorablemente al acuerdo impugnado, para que colabore en la defensa de éste en el juicio de impugnación de acuerdos seguido entre otro accionista y la sociedad.

Por ello, coincidimos en que la regulación de la intervención del tercero en el proceso responde a una necesidad de la administración de justicia en el Perú, a fin de que en lo sucesivo no se repita aquella lacónica y desmotivada providencia: «No siendo parte en el proceso, no ha lugar». 